\title{
CHD4 is recruited by GATA4 and NKX2-5 silencers to repress non-cardiac gene programs in the developing heart
}

Zachary L. Robbe ${ }^{1,7}$, Wei Shi ${ }^{1,7}$, Lauren K. Wasson ${ }^{1}$, Caralynn M. Wilczewski ${ }^{1,2}$, Xinlei Sheng ${ }^{3}$, Austin J. Hepperla ${ }^{4}$, Brynn N. Akerberg ${ }^{5}$, William T. Pu ${ }^{5}$, Ileana M. Cristea ${ }^{3}$, Ian J. Davis ${ }^{4,6}$, Frank L. Conlon ${ }^{1,2,8}$

${ }^{1}$ Departments of Biology and Genetics, University of North Carolina at Chapel Hill, Chapel Hill, $\mathrm{NC}, \mathrm{USA}$

${ }^{2}$ McAllister Heart Institute, University of North Carolina at Chapel Hill, Chapel Hill, NC, USA ${ }^{3}$ Department of Molecular Biology, Princeton University, Princeton, NJ, USA

${ }^{4}$ Lineberger Comprehensive Cancer Center, University of North Carolina at Chapel Hill, Chapel Hill, NC, USA

${ }^{5}$ Department of Cardiology, Boston Children's Hospital, Boston, MA, USA

${ }^{6}$ Department of Pediatrics, University of North Carolina at Chapel Hill, Chapel Hill, NC, USA

${ }^{7}$ These authors contributed equally to this work.

${ }^{8}$ Lead Contact

Corresponding Author: frank_conlon@med.unc.edu

Keywords: NuRD, CHD4, recruitment, cardiac, chromatin remodeling 


\begin{abstract}
The Nucleosome Remodeling and Deacetylase (NuRD) complex is one of the central chromatin remolding complexes that mediate gene repression. NuRD is essential for numerous developmental events, including heart development. Clinical and genetic studies have provided direct evidence for the role of chromodomain helicase DNA-binding protein 4 (CHD4), the catalytic component of $\mathrm{NuRD}$, in congenital heart disease (CHD), including atrial and ventricular septal defects. Further, it has been demonstrated that CHD4 is essential for mammalian cardiomyocyte formation and function. A key unresolved question is how CHD4/NuRD is localized to specific cardiac targets genes, as neither CHD4 nor NuRD can directly bind DNA. Here, we coupled a bioinformatics-based approach with mass spectrometry analyses to demonstrate that CHD4 interacts with the core cardiac transcription factors GATA4, NKX2-5 and TBX5 during embryonic heart development. Using transcriptomics and genome-wide occupancy data, we have characterized the genomic landscape of GATA4, NKX2-5 and TBX5 repression and defined the direct cardiac gene targets of GATA4-CHD4, NKX2-5-CHD4 and TBX5-CHD4 complexes. These data were used to identify putative cis-regulatory elements regulated controlled by these complexes. We genetically interrogated two of these silencers in vivo, Actal and Myh11. We show that deletion of these silencers leads to inappropriate skeletal and smooth muscle gene mis-expression, respectively, in the embryonic heart. These results delineate how CHD4/NuRD is localized to specific cardiac loci and explicates how mutations in the broadly expressed CHD4 protein lead to cardiac specific disease states.
\end{abstract}

\title{
Introduction
}

Transcriptional repression is mediated by broadly expressed multiprotein complexes that 
modify and remodel chromatin. Repression by these complexes is achieved by alteration of chromatin states through direct DNA-sequence-specific binding of a given complex or by recruitment of the complex to defined loci via interactions with tissue-specific transcription factors. The Nucleosome Remodeling and Deacetylase (NuRD) complex represses gene expression and is essential from fly to human. In most cases, the combined histone deacetylase and ATP-dependent chromatin remodeling helicase of NuRD combine to modulate chromatin states at target genes (Wade et al. 1998; Xue et al. 1998; Zhang et al. 1998; Wade et al. 1999). Components of the NuRD complex differ but invariably contain either of the ATP-dependent chromodomain helicases CHD3 or CHD4 (Watson et al. 2012; Joshi et al. 2013; Low et al. 2016; Zhang et al. 2016; Hoffmeister et al. 2017; Farnung et al. 2020). The crucial nature of CHD4 has been established through clinical studies that have shown mutations in CHD4 lead to congenital heart disease (Zaidi et al. 2013; Homsy et al. 2015; Sifrim et al. 2016; Waldron et al. 2016; Weiss et al. 2016). In addition, genetic studies in mouse have demonstrated that cardiac conditional Chd4 null mutants die at mid-gestation and that loss of CHD4-mediated repression leads to misexpression of fast skeletal and smooth muscle myofibril isoforms, cardiac sarcomere malformation and early embryonic lethality (Gomez-Del Arco et al. 2016; Wilczewski et al. 2018).

Though CHD4 is essential for heart development, and its disease relevance has been shown, one of the central unanswered questions regarding the complex's regulatory mechanism is how CHD4/NuRD is recruited to specific cardiac gene loci, given that neither CHD4 nor NuRD bind DNA. Using a genomic approach, we identified overrepresented DNA motifs recognized by several core cardiac transcription factors at CHD4-bound genomic regions. Using parallel reaction monitoring mass spectrometry (PRM nLC-MS/MS) (Picotti et al. 2013; 
Federspiel et al. 2019), we confirmed that CHD4 interacts in vivo in mid-gestation hearts with GATA4, NKX2-5 and TBX5. Further analysis revealed that CHD4 and GATA4, NKX2-5 and TBX5 converge on regulatory elements genome-wide associated with transcriptional repression. These findings imply an important dual regulatory role for these critical cardiac transcription factors.

We have used our data to map putative cardiac cis-regulatory elements (CREs) regulated through GATA4-CHD4, NKX2-5-CHD4, and TBX5-CHD4 complexes. Deletion of a putative CREs at the skeletal muscle Actal gene that contains an NKX2-5 binding site led to inappropriate Actal expression in the fetal heart. Similarly, deletion of a CHD4 CRE of the smooth muscle Myh11 gene containing a GATA4 binding site led to Myh11 mis-expression in the fetal heart. Collectively, our results demonstrate that $\mathrm{CHD} 4 / \mathrm{NuRD}$ is recruited to defined loci through a core set of cardiac transcription factors to repress inappropriate gene expression in the developing heart.

\section{Results}

\section{CHD4 interacts with the core cardiac transcription factors GATA4, NKX2-5, and TBX5}

One of the central issues regarding the mechanism and function of the CHD4/NuRD complex involves the recruitment of CHD4/NuRD to specific loci, given that neither CHD4 nor NuRD bind DNA directly (Figure 1A). To address these issues, we performed motif discovery of CHD4 ChIP-seq data sets obtained from E10.5 hearts (Wilczewski et al. 2018) (GEO:GSE109012). Our analyses revealed a striking abundance of significantly over-represented cardiac transcription factor consensus motifs in CHD4-bound regions (Figure 1B). These sequences included binding sites for the core cardiac transcription factors GATA4, NKX2-5, and TBX5, each of which is required for cardiac development and, when mutated, causes human heart disease (Durocher et 
al. 1997; McCulley and Black 2012; Baban et al. 2014; Akerberg et al. 2019; Jumppanen et al. 2019). Moreover, mice homozygous null for Tbx5, Gata4 and NKX2-5 display heart defects at E10.5, the same developmental stage that requires Chd4 (Bruneau et al. 2001; Stennard et al. 2003; Watt et al. 2004; Mori et al. 2006; Maitra et al. 2009; Terada et al. 2011; Zhou et al. 2015; Gomez-Del Arco et al. 2016; Wilczewski et al. 2018).

We confirmed CHD4 co-localization with GATA4, NKX2-5 and TBX5 by proximity ligation assays (PLA). CHD4 was expressed with either GATA4, NKX2-5, TBX5, or as a negative control, turboGFP (Figures 1C-F). In support of our genomic analyses, we find that CHD4 interacts with GATA4, NKX2-5, and TBX5, and in all three cases, the interaction occurs predominantly in the nucleus.

To elucidate if CHD4 interacts with either GATA4, NKX2-5 or TBX5 in heart tissue in vivo, we performed parallel reaction monitoring MS (PRM LC-MS/MS) on immuno-affinity purified cardiac E10.5 CHD4 interactomes (Figure 1G). Consistent with previous findings (Waldron et al. 2016), PRM LC-MS/MS analysis of E10.5 CHD4 endogenous interactomes revealed CHD4 in complex with TBX5. These analyses also identified that CHD4 is in complex with GATA4 and NKX2-5 in E10.5 hearts (Figure 1G). To our knowledge, this is the first report of an endogenous interaction between CHD4 and NKX2-5 during heart development. Together, our data establish that CHD4 complexes in vivo with GATA4, NKX2-5 and TBX5 during a time point when CHD4 is essential for vertebrate heart development.

\section{GATA4, NKX2-5 and TBX5 are co-bound with CHD4}

To determine if GATA4, NKX2-5, and TBX5 binding sites were prevalent in CHD4 ChIP-seq peaks, we overlapped GATA4, NKX2-5, and TBX5 ChIP-seq datasets (Akerberg et al. 2019) 
with CHD4 ChIP-seq peaks. We observe that the majority of CHD4-bound peaks are also bound by GATA4, NKX2-5, and/or TBX5 (Figure 2A).

As we had previously shown that CHD4 interacts with TBX5 to repress non-cardiac gene programs (Waldron et al. 2016), we hypothesized that the interactions with GATA4 and NKX2-5 have a similar consequence. Therefore, we focused on sites within genes that were also bound by CHD4 and that demonstrated increased RNA levels following CHD4 knock out, supportive of a CHD4 repressive activity (Figure $2 B)(n=3418$ peaks). Gene Ontology analysis of peaks cobound by CHD4 and GATA4, NKX2-5, or TBX5 revealed potential biological differences between the CHD4 interaction with each of these transcription factors. Specifically, CHD4/GATA4 and CHD4/NKX2-5 co-bound peaks were linked to genes associated with hypoxia, angiogenesis, and cell migration. In contrast, CHD4/TBX5-co-bound peaks did not demonstrate this association (Figure 2C).

As there are well-characterized interactions between TBX5, GATA4, and NKX2-5 (Durocher et al. 1997; Jumppanen et al. 2019) we hypothesized that there are genomic loci at which CHD4 binds more than one transcription factor. Of the CHD4-bound peaks in repressed genes, more than half $(\mathrm{n}=1852)$ were co-bound by TBX5, GATA4, and/or NKX2-5 (Figure 2D). Furthermore, we found that 445 peaks at CHD4 repressed genes were bound by all three transcription factors in addition to CHD4 (Figure 2D). GATA4 was found most often to be associated with CHD4-repressed regions and was also the most likely to co-bind with CHD4 individually (Figure 2D).

We next determined the genomic localization of the CHD4/transcription factor binding to determine a potential effect on gene expression. We annotated binding peaks with the nearest target gene feature (Figure 2E). These analyses show that GATA4-CHD4, NKX2-5-CHD4 and 
TBX5-CHD4 are significantly enriched at intergenic, intronic and promoter regions, suggesting that they regulate gene expression, as these sites are associated with CHD4-mediated transcriptional repression(Wilczewski et al. 2018). We next sought to determine if the number of bound transcription factors or their composition affected the magnitude of CHD4 gene repression. To this end, we examined changes in expression in CHD4/GATA-bound, CHD4/NKX2-5-bound, and/or CHD4/TBX5-bound genes (Figure S1). We conclude that the magnitude of CHD4 repression is not dependent upon the identity of the recruiting factor or the number of occupying factors. Thus, CHD4 interaction with GATA4, NKX2-5 and TBX5 is critical for the localization of the complex to target loci, but the composition of the interaction does not affect the extent of transcriptional repression.

\section{GATA4 is the predominant CHD4 co-factor}

Our data infers that, of the three cardiac core transcription factors, GATA4 is the transcription factor most frequently associated with CHD4 (Figure 2D). To determine further the potential role for GATA4 in repression, we mapped GATA4, NKX2-5 and TBX5 ChIP-seq read density across CHD4 repressed regions grouped by number of bound transcription factors (Figure 2A). From the data, we discovered that both NKX2-5 and TBX5 have a lower read density when bound alone than when bound with at least one other factor, the opposite of what is observed for GATA4. We conclude that GATA4 is the predominant cardiac co-factor for recruiting CHD4.

\section{NKX2-5 recruits CHD4 to repress expression of skeletal actin in the embryonic heart}

Strikingly, we found that GATA4 was localized to $82 \%(1166 / 1422)$ of all CHD4-repressed loci. We, therefore, addressed if binding of either NKX2-5 or TBX5 at a single site is sufficient to 
recruit CHD4 at CHD4 repressed genes. We identified putative silenced enhancers in cardiac tissue focusing on target genes that: 1) contained a single binding site for either NKX2-5 or TBX5, 2) demonstrated binding site conservation between mouse and human, 3) were associated with a single CHD4 peak and, 4) were marked by H3K27me3 (Figure 3)(Consortium 2012). Among genes meeting these four criteria was Actal, the gene that encodes a skeletal actin isoform and is an established CHD4/NuRD target (Wilczewski et al. 2018). In the normal developing heart, cardiac actin Actcl is the predominant actin isoform (Mayer et al. 1984) whereas Actal, the skeletal isoform, is expressed at low to undetectable levels. The Actal locus contained a single putative NKX2-5 DNA-binding motif located in the Actal 3'UTR (Figures 4A-C). Thus, the 3'UTR of Actal was postulated to contain a silent enhancer bound by NKX2-5 and CHD4 in E10.5 hearts.

To genetically interrogate whether Actal is repressed in vivo in cardiac tissue thorough this downstream region, we used CRISPR/Cas9 technologies to generate mice in which the putative repressive domain was disrupted $\left(\right.$ Acta $\left.^{\Delta 3^{\prime}}\right)$. These studies reveal that the loss of a single copy of the silent enhancer containing the NKX2-5 binding site in the 3-UTR leads to Acta1 misexpression in E10.5 hearts in a dominant manner (Figure 4D) with mRNA levels of Actal showing a significant increase relative to wild-type littermate controls (Figure 4D). We conclude that a single copy of an NKX2-5 binding site is sufficient to recruit CHD4 and repress expression of a skeletal actin isoform in the developing mammalian heart. These data further show that, in contrast to its established role in gene activation, NKX2-5 can also mediate cardiac transcriptional repression. 


\section{Deletion of a GATA4-CHD4 site in Myh11 leads to its mis-expression in developing mouse hearts}

We identified a single GATA4 binding site within the third intron of Myh11, the gene encoding the smooth muscle myosin heavy chain (SMMHC) protein (Figures 5A, B), an established target of CHD4 (Wilczewski et al. 2018). The canonical GATA4 DNA-binding motif in Myh11 intron 3 was conserved between mouse and human, co-occupied by CHD4 and GATA4, NKX2-5 and TBX5 during fetal heart development, and flanked by H3K27me3 marked chromatin (Figures 5B, C). Consistent with these observations, we found Myh11 expression to be significantly increased in GATA4 mutant hearts versus littermate controls (Figure S2). Interestingly, although we detected strong NKX2-5 and TBX5 ChIP signal, the recognition element for NKX2-5 or TBX5 was not detected in either mouse or human sequence. Thus, it may be that GATA4 recruits NKX2-5 and TBX5 as well as CHD4 to this region.

To test the effect of this resion, we used CRISPR/Cas9 technologies to delete the GATA4 binding region in mice $\left(M y h 11^{\Delta i 3}\right)$ (Hashimoto et al. 2016). Strikingly, we found that deletion of the Myh11 silencer caused a large upregulation of Myh11 in a dominant manner (Figure 5D). Myh11 expression increased approximately 70-fold in E10.5 heart tissue derived from heterozygous $M y h 11^{\Delta i 3 /+}$ mice, whereas in mice homozygous for $M y h 11^{\Delta i 3 / \Delta i 3}$, the deletion increased Myh11 expression by greater than 200-fold. Collectively these data define a novel silencer of Myh11 that is regulated by the GATA4-CHD4 complex in association with NKX2-5 and TBX5 and that is essential to repress Myh11 in the heart.

\section{Discussion}

Although CHD4 and the NuRD complex are well established to function in repressing 
transcription, how CHD4/NuRD is recruited to specific loci remained unknown. Here, we demonstrate that the core cardiac transcription factors GATA4, NKX2-5 and TBX5 interact and recruit CHD4 to defined genomic locations associated with H3K27me3. Our findings reveal that NKX2-5, a cardiac transcription factor that has long been understood to function as a transcriptional activator (McCulley and Black 2012), can also function as a cardiac transcriptional repressor. Our studies further show that NKX2-5 and GATA4 function to repress genes incompatible with heart development and function. Because GATA4, NKX2-5 and TBX5 cause a range of congenital heart disease (Basson et al. 1997; Li et al. 1997; Furtado et al. 2017; Steimle and Moskowitz 2017; Zhang et al. 2017; Behiry et al. 2019), our findings imply that the respective patient phenotypes are not only due to loss of cardiac gene expression but also to mis-expression of non-cardiac genes in the developing heart.

Our data supports the hypothesis that mutations in regulatory regions essential for CHD4-mediated repression act in a dominant manner. This may provide one mechanism for the prevalence of CHD in humans with one mutated copy of NKX2-5, Gata4 or Tbx5. Our findings that CHD4 complexes with temporally and spatially regulated cardiac transcription factors further explicates how mutations in the broadly expressed CHD4 protein lead to cardiac specific disease states.

The findings that GATA4, NKX2-5 and TBX5 can recruit CHD4 to the majority of CHD4 repressed target genes in the heart is broadly consistent with studies in B cells demonstrating interaction of CHD4 with lineage-specific transcription factors (Yoshida et al. 2019). However, analyses of GATA4, NKX2-5, TBX5 or the B cell transcription factors fails to uncover any shared sequence homology, conserved sequences or common motif, even at low stringency, thus raising the question of how this diverse set of transcription 
factors interact with CHD4. Moreover, our analyses of the CHD4 interactome failed to identify any proteins that may function as adapter proteins. Based on these observations, we favor a model by which these sets of transcription factors recognize a secondary structure within CHD4, possibly within or adjacent to the PHD and/or CD domains (Mansfield et al. 2011; Watson et al. 2012; Low et al. 2016; Zhang et al. 2016; Farnung et al. 2020).

CHD4/NuRD is essential for numerous developmental events, such as ensuring proper timing of the switch from stem-cell lineages to differentiated cell types, maintaining cell differentiation, and activating DNA damage response pathways (Larsen et al. 2010; Polo et al. 2010; Scimone et al. 2010; Hosokawa et al. 2013; O'Shaughnessy and Hendrich 2013; Sparmann et al. 2013; Chudnovsky et al. 2014; O'Shaughnessy-Kirwan et al. 2015; GomezDel Arco et al. 2016; Zhao et al. 2017; Ostapcuk et al. 2018; Arends et al. 2019; McKenzie et al. 2019; Yoshida et al. 2019; Hou et al. 2020; Sreenivasan et al. 2021). We purpose that one of the generalized functions of $\mathrm{CHD} 4 / \mathrm{NuRD}$ is to repress the inappropriate activation of developmental programs of a given tissue or cell type. We suggest that alteration in CHD4 recruitment by tissue specific transcription factors lead to the wide range of CHD4 associated disease states.

\section{Methods}

\section{Mice}

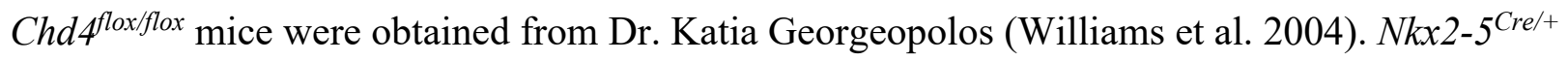
mice were obtained from Robert Schwartz (Moses et al. 2001). Chd4 conditional knockout mice and control littermates were obtained by breeding female $C h d 4^{\text {flox/flox }}$ mice to male $C h d 4^{f l o x /+}$; $\mathrm{Nk} \times 2-5^{\mathrm{Cr} /+}$ mice. CRISPR/Cas9-mediated genome editing was performed by the UNC Animal Models Core Facility. CRISPR founder mice were bred to wild-type C57B16J female mice for two generations. Heterozygous F2 mice were interbred to generate embryos. Research was 
approved by the Institutional Animal Care and Use Committee at the University of North Carolina and conforms to the Guide for the Care and Use of Laboratory Animals.

\section{CRISPR/Cas9 Mediated Mouse Engineering and breeding}

Cas9 guide RNAs flanking the desired deletion regions were identified using Benchling software. Three guide RNAs at each end of the target sequence were selected for activity testing. Guide RNAs were cloned into a $\mathrm{T} 7$ promoter vector followed by in vitro transcription and spin column purification. Functional testing was performed by transfecting a mouse embryonic fibroblast cell line with guide RNA and Cas9 protein. The guide RNA target site was amplified from transfected cells and analyzed by ICE (Synthego). One guide RNA at each end of the target sequence was selected and a donor oligonucleotide was included to facilitate homologous recombination to produce a clean deletion event between the guide RNA cut sites. C57BL/6J zygotes were electroporated with $1.2 \mu \mathrm{M}$ Cas 9 protein, $47 \mathrm{ng} / \mathrm{ul}$ each guide RNA and $400 \mathrm{ng} / \mathrm{ul}$ donor oligonucleotide and implanted in recipient pseudopregnant females. Resulting pups were screened by PCR and sequencing for the presence of the deletion allele. Male founders with the correct deletion were mated to wild-type C57BL/6J females for germline transmission of the deletion allele. The founding Acta $^{\Delta 3^{\prime}}$ and $M y h 11^{\Delta i 3}$ males were bred to wildtype mice for two generations, and the genotypes of Acta $^{\Delta 3^{\prime}}$ ' and $M y h 11^{\Delta i 3}$ founding males and all F2 offspring were confirmed by sequencing and PCR/restriction digests. F2 mice were intercrossed and hearts derived from homozygous, heterozygous, and wildtype littermates were collected and assayed for Actal and Myh11 mis-expression, respectively.

\section{Motif Discovery}

De novo motif discovery on CHD4 chromatin immunoprecipitation followed by high-throughput sequencing (ChIP-seq) regions (Wilczewski et al. 2018) (GSE109012) from embryonic day (E)10.0 cardiac tissue was performed using Hypergeometric Optimization of Motif EnRichment (HOMER) (Heinz et al. 2010).

\section{CHD4 immunoaffinity purification}

E10.5 wild-type CD1 hearts (minimum twenty-eight hearts per IP, three separate biological replicates) were harvested in cold PBS, snap frozen and cryolysed as previously described (Kaltenbrun et al. 2013). Frozen tissue powder was resuspended in optimized lysis buffer (5ml/1g powder) (20mM K-HEPES pH7.4, 0.11M KOAC, $2 \mathrm{mM} \mathrm{MgCl2,} \mathrm{0.1 \%} \mathrm{Tween} \mathrm{20,} 1 \mu \mathrm{M}$ $\mathrm{ZnCl} 2,1 \mathrm{mM} \mathrm{CaCl} 2,0.5 \%$ Triton-X 100, 150mM NaCl2, protease inhibitor (Sigma), phosphatase inhibitor (Sigma)). CHD4 complexes were solubilized and immunoaffinity purified as previously described (Cristea and Chait 2011; Kaltenbrun et al. 2013) using rabbit anti-CHD4 antibody (Abcam \#ab72418) or negative control custom rabbit anti-GFP antibody (Cristea et al. $2005)$ with elution at $95^{\circ} \mathrm{C}$ for 10 minutes. The immunoisolated proteins were resolved $(\sim 1 \mathrm{~cm})$ 
by SDS-PAGE, and visualized by Coomassie blue. Each lane was subjected to in-gel digestion with trypsin as previously reported (Waldron et al. 2016).

\section{(Parallel Reaction Monitoring) PRM nLC-MS/MS}

Immunoisolated proteins were resolved $(\sim 1 \mathrm{~cm})$ by SDS-PAGE, and visualized by Coomassie blue. Each lane was subjected to in-gel digestion with trypsin as previously reported (Waldron et al. 2016). Desalted peptides ( $2 \mu \mathrm{l}$ each) were analyzed by nano-liquid chromatography (nLC)MS/MS using a Dionex Ultimate $3000 \mathrm{nRSLC}$ system directly coupled to a Q-exactive HF orbitrap mass spectrometer (ThermoFisher Scientific) equipped with an EASY-Spray ion source (Thermo, Fisher Scientific). Peptide mixtures were evaporated in vacuo and resuspended in 1\% Trifluoroacetic acid/4\%acetonitrile/95\% water and loaded onto an $50 \mathrm{~cm}$ long column with a 75 um internal diameter (PepMap) and separated over a 60 min gradient with a mobile phase containing aqueous acetonitrile and $0.1 \%$ formic acid programmed from $1 \%$ to $3 \%$ acetonitrile over $12 \mathrm{~min}$, then 3 to $35 \%$ acetonitrile over $60 \mathrm{~min}$, then 35 to $97 \%$ acetonitrile over $1 \mathrm{~min}$, followed by $10 \mathrm{~min}$ at $97 \%$ acetonitrile and 97 to $70 \%$ over $1 \mathrm{~min}$, all at a flow rate of 250 $\mathrm{nL} / \mathrm{min}$.

The PRM analysis was carried out as previously reported(Justice et al. 2021). Briefly, the method consisted of targeted MS2 scans at a resolution of 60,000 and with an AGC value of $1 \times 10^{6}$, a max injection time of $500 \mathrm{~ms}$, a $0.8 \mathrm{~m} / \mathrm{z}$ isolation window, a fixed first mass of $150 \mathrm{~m} / \mathrm{z}$, and normalized collision energy of 27 , which were recorded as profile data. The targeted MS2 methods were controlled with a timed inclusion list containing the target precursor $\mathrm{m} / \mathrm{z}$ value, charge, and a retention time window that were determined from shotgun analysis.

cDNA synthesis and qPCR

RNA from individual E10.5 hearts ( $\mathrm{N}=3$ or 5 per genotype) was isolated using the RNAqueousMicro Total RNA Isolation Kit following manufacturer recommended protocols (Invitrogen). cDNA synthesis was performed using random hexamers and SuperScript IV reverse transcriptase (Invitrogen). Quantitative PCR was performed using PowerUP SYBR Green Master Mix (ThermoFisher) at standard cycling conditions on a QuantStudio 6 Flex instrument (ThermoFisher) with the following primers:

Myh11 F1: GCTAATCCACCCCCGGAGTA

Myh11 R1: TCGCTGAGCTGCCCTTTCT

Actal F1: GTGACCACAGCTGAACGTG

Actal R1: CCAGGGAGGAGGAAGAGG

Pgk1 F1: GTCGTGATGAGGGTGGACTT

Pgk1 R1: AAGGACAACGGACTTGGCTC

Proximity ligation assay (PLA) 
A standardized procedure for PLA was used (Jalili et al. 2018). Briefly, HEK-293 cells were seeded on circular coverslips and transfected with specific plasmids for 72 hours using a 3:1 ratio of PEI to pDNA. Cells were fixed with $4 \%$ paraformaldehyde for 10 minutes, followed by permeabilization and blocking (10\% heat-inactivated goat-serum, 1\% Triton-X 100) for 1 hour. Cells were then probed with two specific primary antibodies raised in different species, mouse anti-TurboGFP (1:250, Origene, TA150041) / rabbit anti-Flag (1:500, Sigma, F7425) overnight at $4{ }^{\circ} \mathrm{C}$. The cells were incubated with PLA probes for $1 \mathrm{hr}$ at $37^{\circ} \mathrm{C}$, with ligase for $30 \mathrm{~min}$ at 37 ${ }^{\circ} \mathrm{C}$ and with polymerase for $100 \mathrm{~min}$ at $37^{\circ} \mathrm{C}$, based on manufacturer protocols. Cells were stained with DAPI and then mounted with PermaFluor mounting medium (ThermoScientific TA030FM). Images were captured on a Zeiss LSM 700 laser scanning confocal microscope.

\section{DNA Constructs}

Full length human $C H D 4$ tagged at C-terminus with Flag/Myc construct was obtained from Origene (RC224232). Full-length human GATA4 cDNA was amplified with 5' primer (ATTAGCGATCGCCATGTATCAG) and 3' primer (CGTACGCGTCGCAGTGAT). Amplicons were digested with restriction enzymes AsiSI / MluI and inserted into pCMV6-ACturboGFP vector (Origene, PS100010). Full-length human NKX2-5 cDNA was amplified with 5' primer (ATTAGGATCCATGTTCCCCAGCCCTG) and 3' primer (GTCGACTCACCAGGCTCGGATACCAT). Amplicons were digested with restriction enzymes AsiSI / MluI and inserted into pCMV6-AC-turboGFP vector (Origene, PS100010).

\section{NGS Datasets Used}

GATA4 Genome Occupancy at E12.5 in the developing mouse heart (GEO:GSE52123) (He et al. 2014).

NKX2-5 Genome Occupancy at E12.5 in the developing mouse heart (GEO:GSE124008) (Akerberg et al. 2019)

TBX5 Genome Occupancy at E12.5 in the developing mouse heart (GEO:GSE124008) (Akerberg et al. 2019)

CHD4 Genome Occupancy at E10.0 in the developing mouse heart (GEO:GSE109012) (Wilczewski et al. 2018)

CHD4 Transcriptomics at E10.5 in the developing mouse heart (GEO:GSE109012) (Wilczewski et al. 2018)

H3K27me3 Histone Modification at E10.5 in the developing mouse heart (GEO:GSE86693) (Consortium 2012)

\section{Genome Annotation and Co-Occupancy Analysis}

BAM and BED files were obtained from the Gene Expression Omnibus aligned to mm10. Peaks were called using MACS2 (v2.2.7.1) (Zhang et al. 2008) using default settings with a q-value of 
0.01. High confidence peaks appearing in both replicates were retained for downstream analysis. Peak annotation was conducted with HOMER (v4.10) (Heinz et al. 2010). Peaks were annotated using the ChIP-Seeker (v1.24.0) R package(Yu et al. 2015). Biological Process GO terms for pe ak regions were generated using R package ClusterProfiler (Qian et al. 2012). Gene tracks were visualized using IGV (Robinson et al. 2011). Peak overlaps were determined using BedTools, an $\mathrm{d}$ the upset plot was generated using UpSetR v1.4.0(Conway et al. 2017) in R. Overlaps between CHD4, GATA4, NKX2-5, TBX5, and H3K4me3 were plotted in relation to their chromosomal 1 ocation using the karyoploteR (v1.14.0) R package(Gel and Serra 2017).

\section{Competing interest statement}

The authors declare no competing interests.

\section{Acknowledgements}

This work was supported by grants R01HL156424 NIH/NHLBI to F.L.C, R01HD089275 NIH

/NHLBI to F.L.C. and I.M.C., and 2UM1HL098166 to W.T.P.

Author contributions: Z.R., W.S., and F.C. designed most of the experiments. Z.R., W.S., and

C.W. performed RNA-seq, B.A. performed the ChIP-seq. Z.R., W.S., L.W., C.W., A.H., and

B.A. performed and interpreted the bioinformatic analyses. Z.R., C.W, and X.S. performed the

IP/PRM-MS experiments and analyses. Z.R. and W.S. generated the knockout mouse lines and

performed the RT-qPCR. W.P., I.C., I.D., and F.C. supervised the project. Z.R., W.S., L.W., and

F.C. wrote the manuscript with feedback from all authors. 


\section{Figure Legends}

Figure 1. CHD4 Interacts with Core Cardiac TFs: GATA4, NKX2-5, and TBX5.

(A) Schematic of the Nucleosome Remodeling and Deacetylase (NuRD) complex localizing to target loci through interaction with a tissue-specific co-factor. (B) Predicted co-occupancy of CHD4 and GATA4, NKX2-5, and TBX5 through significant overrepresentation of known binding motifs of each factor in CHD4 bound genomic regions. q values $=0.0000$ generated from FDR-corrected $\mathrm{P}$ value based on the cumulative hypergeometric distribution. (C-F) CHD4 associates with GATA4, NKX2-5, and TBX5 through proximity ligation assay. Each image shown as a max intensity z-stack projection using a 63xoil magnification objective. Presence of PLA signal (white dots) denotes close physical proximity of target proteins and represents a physical interaction. CHD4 and turboGFP alone $(\mathrm{C})$ result in a lower frequency and intensity of PLA signal than CHD4-GATA4 (D), CHD4-NKX2-5 (E), or CHD4-TBX5 (F). (G) CHD4 complexes affinity purified from wild-type E10.5 mouse embryonic hearts show a significant enrichment for peptides belonging to GATA4, TBX5, or NKX2-5 when compared to purified GFP complexes, as determined by PRM-MS quantification and Student's t test. Data shown as mean \pm SEM of triplicates, $n=3$, with each replicate of $>28$ pooled embryonic hearts per IP. $* * * * \mathrm{P}$ value $<0.0001$

Figure 2. CHD4 Co-occupies Directly Repressed Loci with GATA4, NKX2-5, and TBX5 (A) Heatmap visualizing density of ChIP-seq signal of each transcription factor (GATA4, NKX2-5, and TBX5) across genomic regions occupied by CHD4 in the developing heart. (B) Overlap of genes bound by CHD4 and upregulated in Chd4-null hearts. 733/920 (80\%) of genes upregulated in hearts devoid of CHD4 are also bound by CHD4 at E10.5. These 733 genes are 
termed CHD4-repressed genes and are associated with 3418 peaks. (C) Biological processes overrepresented in regions co-occupied and repressed by CHD4-GATA4, CHD4-NKX2-5, and CHD4-TBX5. The heatmap is presented as the -log Bonferroni corrected $\mathrm{P}$ value. Gray boxes represent Biological Processes with a non-significant P-value for that group. (D) Upset plot displaying intersection of ChIP-seq peaks shared between CHD4 and GATA4, NKX2-5 and TBX5, respectively. Each column represents a different possible overlap of the data, with the totals defined with the horizontal-colored bars. CHD4 peaks that did not overlap with any transcription factor are not depicted in this plot (E) Stacked bar plot visualizing the distribution of peaks to their associated gene feature annotated using ChIP-Seeker. Columns represent transcription factor peaks associated with CHD4-repressed genes or other regions. Statistical significance was calculated using a t-test, comparing each column to GNT.

Figure 3. GATA4, NKX2-5, and TBX5 are Associated with H3K27me3 at CHD4-repressed Genes

Sites of CHD4 and transcription factor association at CHD4-repressed genes marked with H3K27me3 histone modification at a chromosome level.

Figure 4. Silencer Downstream of Actal Controlled by CHD4 and NKX2-5 is Required for Repression of Actal at E10.5.

(A) NKX2-5-mediated recruitment of CHD4 to target repressor downstream of the TTS in the Actal locus. Putative NKX2-5 motif was identified through motif analysis. (B) Visualization by IGV of ChIP-seq signal across the Actal locus. The repressor region is highlighted with a yellow rectangle. (C) Sequence conservation of CRISPR-deleted region between human and mouse. Red 
box denotes predicted NKX2-5 binding motif and shows strong conservation with human sequence. (D) Relative expression of Actal in E10.5 embryonic hearts when repressor region excised from one or both alleles. Significance was assessed using an unpaired two-tailed Student's t test. $* * \mathrm{P}$ value $<0.01, * * * \mathrm{P}$ value $<0.001, \mathrm{n}=5$ non-pooled hearts per genotype. Data normalized to expression of Pgkl.

Figure 5. Repressor Region in Myh11 Controlled by CHD4 and GATA4, NKX2-5, and TBX5 is Required for Repression of Myh11 at E10.5.

(A) Schematic demonstrating GATA4-mediated recruitment of CHD4 to target repressor in the third intron of Myh11. A putative GATA4 binding motif was identified through motif analysis using HOMER. (B) IGV Genomic visualization of ChIP-seq signal of of GATA4, NKX2-5, TBX5, CHD4, and H3K27me3 across the Myh11 locus. The repressor region is highlighted with a yellow bar. (C) Sequence conservation of CRISPR-deleted region between human and mouse. The red box denotes the predicted GATA4 binding motif and shows strong conservation with human sequence. (D) Relative expression of Myh11 in E10.5 embryonic hearts when the repressor region was excised in one or both alleles. Significance assessed with unpaired twotailed Student's t test. * $\mathrm{P}$ value $<0.05, * * \mathrm{P}$ value $<0.01, \mathrm{n}=3$ non-pooled hearts per genotype. Data normalized to expression of Pgkl.

Figure S1. Change in expression of significanly repressed genes at E10.5 in CHD4 conditional knockout hearts. Genes were grouped by CHD4 association with one or a combination of GATA4, NKX2-5 and TBX5. Data is presented as median log2 (Fold-Change) and interquartile ranges. 
Figure S2. Fragments Per Kilobase of transcript per Million (FPKM) mapped reads of Myh11 in

RNA-seq of Gata4 $\mathrm{KO}$ hearts.

\section{References:}

Akerberg BN, Gu F, VanDusen NJ, Zhang X, Dong R, Li K, Zhang B, Zhou B, Sethi I, Ma Q et al. 2019. A reference map of murine cardiac transcription factor chromatin occupancy identifies dynamic and conserved enhancers. Nat Commun 10: 4907.

Arends T, Dege C, Bortnick A, Danhorn T, Knapp JR, Jia H, Harmacek L, Fleenor CJ, Straign D, Walton K et al. 2019. CHD4 is essential for transcriptional repression and lineage progression in $B$ lymphopoiesis. Proc Natl Acad Sci U S A 116: 10927-10936.

Baban A, Pitto L, Pulignani S, Cresci M, Mariani L, Gambacciani C, Digilio MC, Pongiglione G, Albanese S. 2014. Holt-Oram syndrome with intermediate atrioventricular canal defect, and aortic coarctation: functional characterization of a de novo TBX5 mutation. Am J Med Genet A 164A: 1419-1424.

Basson CT, Bachinsky DR, Lin RC, Levi T, Elkins JA, Soults J, Grayzel D, Kroumpouzou E, Traill TA, LeblancStraceski J et al. 1997. Mutations in human TBX5 [corrected] cause limb and cardiac malformation in Holt-Oram syndrome. Nature Genetics 15: 30-35.

Behiry EG, Al-Azzouny MA, Sabry D, Behairy OG, Salem NE. 2019. Association of NKX2-5, GATA4, and TBX5 polymorphisms with congenital heart disease in Egyptian children. Molecular Genetics \& Genomic Medicine 7: e612.

Bruneau BG, Nemer G, Schmitt JP, Charron F, Robitaille L, Caron S, Conner DA, Gessler M, Nemer M, Seidman CE et al. 2001. A murine model of Holt-Oram syndrome defines roles of the T-box transcription factor Tbx5 in cardiogenesis and disease. Cell 106: 709-721.

Chudnovsky Y, Kim D, Zheng S, Whyte WA, Bansal M, Bray MA, Gopal S, Theisen MA, Bilodeau S, Thiru P et al. 2014. ZFHX4 interacts with the NuRD core member CHD4 and regulates the glioblastoma tumor-initiating cell state. Cell Rep 6: 313-324.

Consortium EP. 2012. An integrated encyclopedia of DNA elements in the human genome. Nature 489: 57-74.

Conway JR, Lex A, Gehlenborg N. 2017. UpSetR: an R package for the visualization of intersecting sets and their properties. Bioinformatics 33: 2938-2940.

Cristea IM, Chait BT. 2011. Affinity purification of protein complexes. Cold Spring Harb Protoc 2011: pdb prot5611.

Cristea IM, Williams R, Chait BT, Rout MP. 2005. Fluorescent proteins as proteomic probes. Mol Cell Proteomics 4: 1933-1941.

Durocher D, Charron F, Warren R, Schwartz RJ, Nemer M. 1997. The cardiac transcription factors Nkx2-5 and GATA-4 are mutual cofactors. EMBO J 16: 5687-5696.

Farnung L, Ochmann M, Cramer P. 2020. Nucleosome-CHD4 chromatin remodeler structure maps human disease mutations. Elife 9.

Federspiel JD, Tandon P, Wilczewski CM, Wasson L, Herring LE, Venkatesh SS, Cristea IM, Conlon FL. 2019. Conservation and divergence of protein pathways in the vertebrate heart. PLOS Biol 17: e3000437.

Furtado MB, Wilmanns JC, Chandran A, Perera J, Hon O, Biben C, Willow TJ, Nim HT, Kaur G, Simonds S et al. 2017. Point mutations in murine Nkx2-5 phenocopy human congenital heart disease and induce pathogenic Wnt signaling. JCl insight 2: e88271. 
Gel B, Serra E. 2017. karyoploteR: an R/Bioconductor package to plot customizable genomes displaying arbitrary data. Bioinformatics 33: 3088-3090.

Gomez-Del Arco P, Perdiguero E, Yunes-Leites PS, Acin-Perez R, Zeini M, Garcia-Gomez A, Sreenivasan K, Jimenez-Alcazar M, Segales J, Lopez-Maderuelo D et al. 2016. The Chromatin Remodeling Complex Chd4/NuRD Controls Striated Muscle Identity and Metabolic Homeostasis. Cell Metab 23: 881-892.

Hashimoto M, Yamashita Y, Takemoto T. 2016. Electroporation of Cas9 protein/sgRNA into early pronuclear zygotes generates non-mosaic mutants in the mouse. Dev Biol 418: 1-9.

He A, Gu F, Hu Y, Ma Q, Ye LY, Akiyama JA, Visel A, Pennacchio LA, Pu WT. 2014. Dynamic GATA4 enhancers shape the chromatin landscape central to heart development and disease. Nat Commun 5: 4907.

Heinz S, Benner C, Spann N, Bertolino E, Lin YC, Laslo P, Cheng JX, Murre C, Singh H, Glass CK. 2010. Simple combinations of lineage-determining transcription factors prime cis-regulatory elements required for macrophage and $B$ cell identities. Mol Cell 38: 576-589.

Hoffmeister H, Fuchs A, Erdel F, Pinz S, Gröbner-Ferreira R, Bruckmann A, Deutzmann R, Schwartz U, Maldonado R, Huber $\mathrm{C}$ et al. 2017. CHD3 and CHD4 form distinct NuRD complexes with different yet overlapping functionality. Nucleic Acids Research 45: 10534-10554.

Homsy J, Zaidi S, Shen Y, Ware JS, Samocha KE, Karczewski KJ, DePalma SR, McKean D, Wakimoto H, Gorham J et al. 2015. De novo mutations in congenital heart disease with neurodevelopmental and other congenital anomalies. Science 350: 1262-1266.

Hosokawa H, Tanaka T, Suzuki Y, Iwamura C, Ohkubo S, Endoh K, Kato M, Endo Y, Onodera A, Tumes DJ et al. 2013. Functionally distinct Gata3/Chd4 complexes coordinately establish T helper 2 (Th2) cell identity. Proc Natl Acad Sci U S A 110: 4691-4696.

Hou T, Cao Z, Zhang J, Tang M, Tian Y, Li Y, Lu X, Chen Y, Wang H, Wei FZ et al. 2020. SIRT6 coordinates with CHD4 to promote chromatin relaxation and DNA repair. Nucleic Acids Res 48: 2982-3000.

Jalili R, Horecka J, Swartz JR, Davis RW, Persson HHJ. 2018. Streamlined circular proximity ligation assay provides high stringency and compatibility with low-affinity antibodies. Proc Natl Acad Sci U S A 115: E925-E933.

Joshi P, Greco TM, Guise AJ, Luo Y, Yu F, Nesvizhskii AI, Cristea IM. 2013. The functional interactome landscape of the human histone deacetylase family. Mol Syst Biol 9: 672.

Jumppanen M, Kinnunen SM, Valimaki MJ, Talman V, Auno S, Bruun T, Boije Af Gennas G, Xhaard H, Aumuller IB, Ruskoaho H et al. 2019. Synthesis, Identification, and Structure-Activity Relationship Analysis of GATA4 and NKX2-5 Protein-Protein Interaction Modulators. J Med Chem 62: 8284-8310.

Justice JL, Kennedy MA, Hutton JE, Liu D, Song B, Phelan B, Cristea IM. 2021. Systematic profiling of protein complex dynamics reveals DNA-PK phosphorylation of IFI16 en route to herpesvirus immunity. Sci Adv 7.

Kaltenbrun E, Greco TM, Slagle CE, Kennedy LM, Li T, Cristea IM, Conlon FL. 2013. A Gro/TLE-NuRD corepressor complex facilitates Tbx20-dependent transcriptional repression. Journal of proteome research 12: 5395-5409.

Larsen DH, Poinsignon C, Gudjonsson T, Dinant C, Payne MR, Hari FJ, Rendtlew Danielsen JM, Menard P, Sand JC, Stucki M et al. 2010. The chromatin-remodeling factor CHD4 coordinates signaling and repair after DNA damage. J Cell Biol 190: 731-740.

Li QY, Newbury-Ecob RA, Terrett JA, Wilson DI, Curtis AR, Yi CH, Gebuhr T, Bullen PJ, Robson SC, Strachan T et al. 1997. Holt-Oram syndrome is caused by mutations in TBX5, a member of the Brachyury (T) gene family. Nature Genetics 15: 21-29. 
Low JK, Webb SR, Silva AP, Saathoff H, Ryan DP, Torrado M, Brofelth M, Parker BL, Shepherd NE, Mackay JP. 2016. CHD4 Is a Peripheral Component of the Nucleosome Remodeling and Deacetylase Complex. J Biol Chem 291: 15853-15866.

Maitra M, Schluterman MK, Nichols HA, Richardson JA, Lo CW, Srivastava D, Garg V. 2009. Interaction of Gata4 and Gata6 with Tbx5 is critical for normal cardiac development. Dev Bio/ 326: 368-377.

Mansfield RE, Musselman CA, Kwan AH, Oliver SS, Garske AL, Davrazou F, Denu JM, Kutateladze TG, Mackay JP. 2011. Plant homeodomain (PHD) fingers of CHD4 are histone H3-binding modules with preference for unmodified H3K4 and methylated H3K9. J Biol Chem 286: 11779-11791.

Mayer Y, Czosnek H, Zeelon PE, Yaffe D, Nudel U. 1984. Expression of the genes coding for the skeletal muscle and cardiac actions in the heart. Nucleic Acids Res 12: 1087-1100.

McCulley DJ, Black BL. 2012. Transcription factor pathways and congenital heart disease. Curr Top Dev Biol 100: 253-277.

McKenzie LD, LeClair JW, Miller KN, Strong AD, Chan HL, Oates EL, Ligon KL, Brennan CW, Chheda MG. 2019. CHD4 regulates the DNA damage response and RAD51 expression in glioblastoma. Sci Rep 9: 4444.

Mori AD, Zhu Y, Vahora I, Nieman B, Koshiba-Takeuchi K, Davidson L, Pizard A, Seidman JG, Seidman CE, Chen XJ et al. 2006. Tbx5-dependent rheostatic control of cardiac gene expression and morphogenesis. Dev Biol 297: 566-586.

Moses KA, DeMayo F, Braun RM, Reecy JL, Schwartz RJ. 2001. Embryonic expression of an Nkx2-5/Cre gene using ROSA26 reporter mice. Genesis 31: 176-180.

O'Shaughnessy A, Hendrich B. 2013. CHD4 in the DNA-damage response and cell cycle progression: not so NuRDy now. Biochem Soc Trans 41: 777-782.

O'Shaughnessy-Kirwan A, Signolet J, Costello I, Gharbi S, Hendrich B. 2015. Constraint of gene expression by the chromatin remodelling protein CHD4 facilitates lineage specification. Development (Cambridge, England) 142: 2586-2597.

Ostapcuk V, Mohn F, Carl SH, Basters A, Hess D, lesmantavicius V, Lampersberger L, Flemr M, Pandey A, Thoma NH et al. 2018. Activity-dependent neuroprotective protein recruits HP1 and CHD4 to control lineage-specifying genes. Nature 557: 739-743.

Picotti P, Clement-Ziza M, Lam H, Campbell DS, Schmidt A, Deutsch EW, Rost H, Sun Z, Rinner O, Reiter L et al. 2013. A complete mass-spectrometric map of the yeast proteome applied to quantitative trait analysis. Nature 494: 266-270.

Polo SE, Kaidi A, Baskcomb L, Galanty Y, Jackson SP. 2010. Regulation of DNA-damage responses and cell-cycle progression by the chromatin remodelling factor CHD4. EMBO J 29: 3130-3139.

Qian L, Huang Y, Spencer Cl, Foley A, Vedantham V, Liu L, Conway SJ, Fu J-d, Srivastava D. 2012. In vivo reprogramming of murine cardiac fibroblasts into induced cardiomyocytes. Nature 485: 593598.

Robinson JT, Thorvaldsdottir H, Winckler W, Guttman M, Lander ES, Getz G, Mesirov JP. 2011. Integrative genomics viewer. Nat Biotechnol 29: 24-26.

Scimone ML, Meisel J, Reddien PW. 2010. The Mi-2-like Smed-CHD4 gene is required for stem cell differentiation in the planarian Schmidtea mediterranea. Development 137: 1231-1241.

Sifrim A, Hitz MP, Wilsdon A, Breckpot J, Turki SH, Thienpont B, McRae J, Fitzgerald TW, Singh T, Swaminathan GJ et al. 2016. Distinct genetic architectures for syndromic and nonsyndromic congenital heart defects identified by exome sequencing. Nat Genet 48: 1060-1065.

Sparmann A, Xie Y, Verhoeven E, Vermeulen M, Lancini C, Gargiulo G, Hulsman D, Mann M, Knoblich JA, van Lohuizen M. 2013. The chromodomain helicase Chd4 is required for Polycomb-mediated inhibition of astroglial differentiation. EMBO J 32: 1598-1612. 
Sreenivasan K, Rodriguez-delaRosa A, Kim J, Mesquita D, Segales J, Arco PG, Espejo I, lanni A, Di Croce L, Relaix F et al. 2021. CHD4 ensures stem cell lineage fidelity during skeletal muscle regeneration. Stem Cell Reports 16: 2089-2098.

Steimle JD, Moskowitz IP. 2017. TBX5: A Key Regulator of Heart Development. Current topics in developmental biology 122: 195-221.

Stennard FA, Costa MW, Elliott DA, Rankin S, Haast SJ, Lai D, McDonald LP, Niederreither K, Dolle P, Bruneau BG et al. 2003. Cardiac T-box factor Tbx20 directly interacts with Nkx2-5, GATA4, and GATA5 in regulation of gene expression in the developing heart. Dev Biol 262: 206-224.

Terada R, Warren S, Lu JT, Chien KR, Wessels A, Kasahara H. 2011. Ablation of Nkx2-5 at mid-embryonic stage results in premature lethality and cardiac malformation. Cardiovasc Res 91: 289-299.

Wade PA, Gegonne A, Jones PL, Ballestar E, Aubry F, Wolffe AP. 1999. Mi-2 complex couples DNA methylation to chromatin remodelling and histone deacetylation. Nat Genet 23: 62-66.

Wade PA, Jones PL, Vermaak D, Wolffe AP. 1998. A multiple subunit Mi-2 histone deacetylase from Xenopus laevis cofractionates with an associated Snf2 superfamily ATPase. Curr Biol 8: 843-846.

Waldron L, Steimle JD, Greco TM, Gomez NC, Dorr KM, Kweon J, Temple B, Yang XH, Wilczewski CM, Davis IJ et al. 2016. The cardiac TBX5 interactome reveals a chromatin remodeling network essential for cardiac septation. Developmental cell 36: 262-275.

Watson AA, Mahajan P, Mertens HD, Deery MJ, Zhang W, Pham P, Du X, Bartke T, Zhang W, Edlich C et al. 2012. The PHD and chromo domains regulate the ATPase activity of the human chromatin remodeler CHD4. J Mol Biol 422: 3-17.

Watt AJ, Battle MA, Li J, Duncan SA. 2004. GATA4 is essential for formation of the proepicardium and regulates cardiogenesis. Proc Natl Acad Sci U S A 101: 12573-12578.

Weiss K, Terhal PA, Cohen L, Bruccoleri M, Irving M, Martinez AF, Rosenfeld JA, Machol K, Yang Y, Liu P et al. 2016. De Novo Mutations in CHD4, an ATP-Dependent Chromatin Remodeler Gene, Cause an Intellectual Disability Syndrome with Distinctive Dysmorphisms. Am J Hum Genet 99: 934941.

Wilczewski CM, Hepperla AJ, Shimbo T, Wasson L, Robbe ZL, Davis IJ, Wade PA, Conlon FL. 2018. CHD4 and the NuRD complex directly control cardiac sarcomere formation. Proceedings of the National Academy of Sciences of the United States of America 115: 6727-6732.

Williams CJ, Naito T, Arco PG, Seavitt JR, Cashman SM, De Souza B, Qi X, Keables P, Von Andrian UH, Georgopoulos K. 2004. The chromatin remodeler Mi-2beta is required for CD4 expression and T cell development. Immunity 20: 719-733.

Xue Y, Wong J, Moreno GT, Young MK, Cote J, Wang W. 1998. NURD, a novel complex with both ATPdependent chromatin-remodeling and histone deacetylase activities. Mol Cell 2: 851-861.

Yoshida T, Hu Y, Zhang Z, Emmanuel AO, Galani K, Muhire B, Snippert HJ, Williams CJ, Tolstorukov MY, Gounari $\mathrm{F}$ et al. 2019. Chromatin restriction by the nucleosome remodeler Mi-2 $\beta$ and functional interplay with lineage-specific transcription regulators control B-cell differentiation. Genes \& Development 33: 763-781.

Yu G, Wang LG, He QY. 2015. ChIPseeker: an R/Bioconductor package for ChIP peak annotation, comparison and visualization. Bioinformatics 31: 2382-2383.

Zaidi S, Choi M, Wakimoto H, Ma L, Jiang J, Overton JD, Romano-Adesman A, Bjornson RD, Breitbart RE, Brown KK et al. 2013. De novo mutations in histone-modifying genes in congenital heart disease. Nature 498: 220-223.

Zhang W, Aubert A, Gomez de Segura JM, Karuppasamy M, Basu S, Murthy AS, Diamante A, Drury TA, Balmer J, Cramard J et al. 2016. The Nucleosome Remodeling and Deacetylase Complex NuRD Is Built from Preformed Catalytically Active Sub-modules. J Mol Biol 428: 2931-2942.

Zhang Y, Ai F, Zheng J, Peng B. 2017. Associations of GATA4 genetic mutations with the risk of congenital heart disease: A meta-analysis. Medicine 96: e6857. 
Zhang Y, LeRoy G, Seelig H, Lane W, Reinberg D. 1998. The dermatomyositis-specific autoantigen Mi2 is a component of a complex containing histone deacetylase and nucleosome remodeling activities. Cell 95: 279 - 289.

Zhang Y, Liu T, Meyer CA, Eeckhoute J, Johnson DS, Bernstein BE, Nusbaum C, Myers RM, Brown M, Li W et al. 2008. Model-based analysis of ChIP-Seq (MACS). Genome Biol 9: R137.

Zhao H, Han Z, Liu X, Gu J, Tang F, Wei G, Jin Y. 2017. The chromatin remodeler Chd4 maintains embryonic stem cell identity by controlling pluripotency- and differentiation-associated genes. $J$ Biol Chem 292: 8507-8519.

Zhou L, Liu J, Olson P, Zhang K, Wynne J, Xie L. 2015. Tbx5 and Osr1 interact to regulate posterior second heart field cell cycle progression for cardiac septation. J Mol Cell Cardiol 85: 1-12. 

Figure 1 bioRxiv preprint doi: https://doi.org/10.1101/2021.10.28.466285; this version posted October 28,2021 . The copyright holder for t
(which was not certified by peer review) is the author/funder, who has granted bioRxiv a license to display the preprint in perpetuit available under aCC-BY-NC-ND 4.0 International license.

A

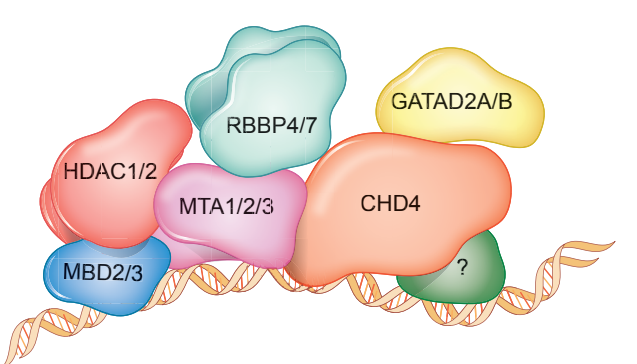

B

\begin{tabular}{|c|c|c|}
\hline Consensus Sequence & Motif Name & q-value \\
\hline 르소소A & GATA4 & 0 \\
\hline AACCACTCAA & NKX2.5 & 0 \\
\hline AGGTGTCA & TBX5 & 0 \\
\hline
\end{tabular}

CHD4 +

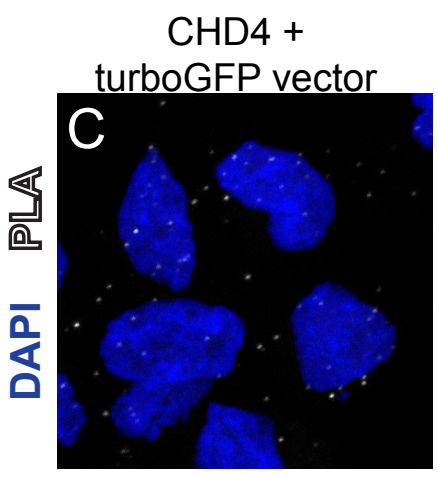

CHD4 + GATA4
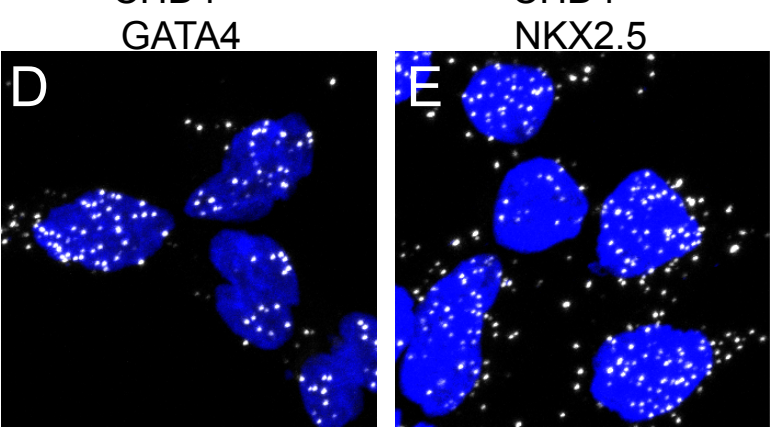

CHD4 +

CHD4 + TBX5

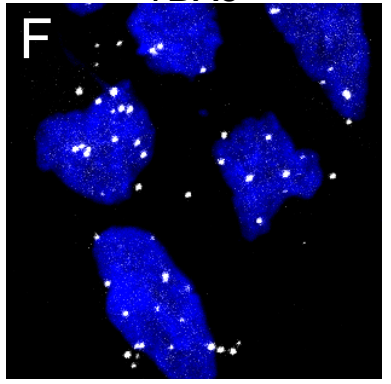

G
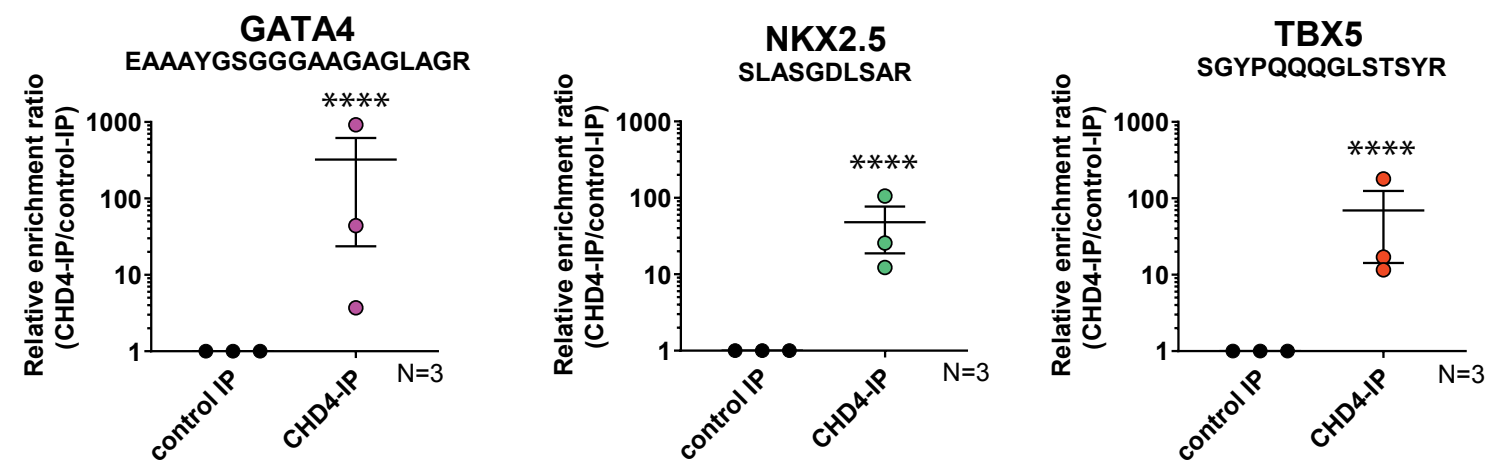

Ð్ల 


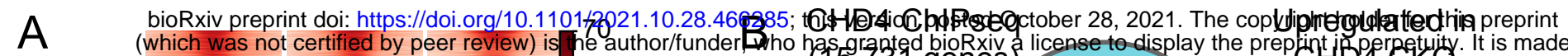

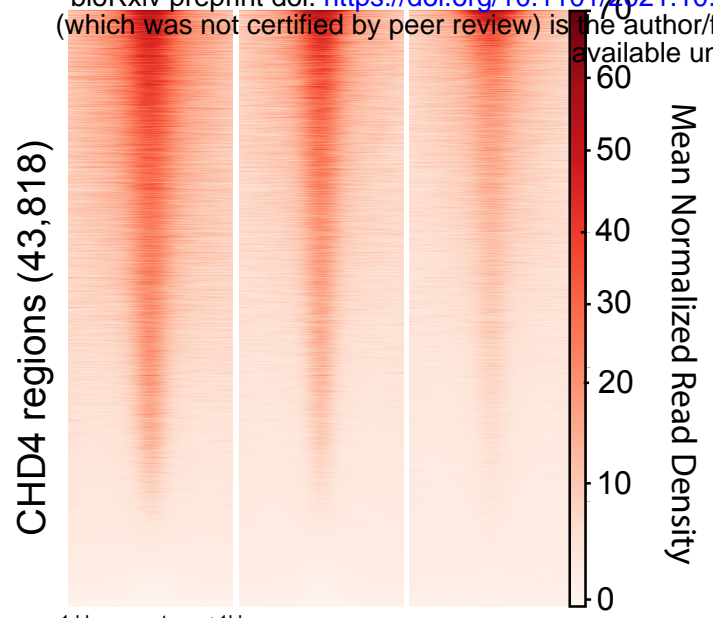
$\begin{array}{ll} & \\ & \end{array}$

GATA4 NKX2.5 TBX5

C

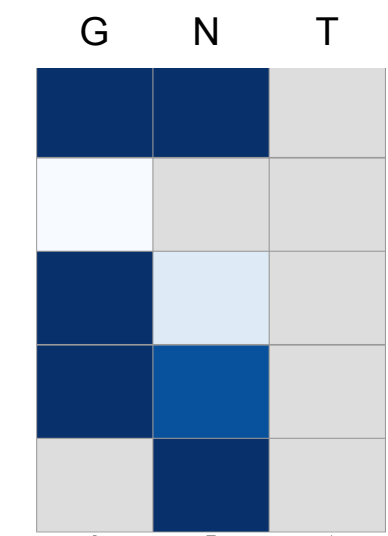

response to hypoxia

regulation of angiogenesis

regulation of cell migration

negative regulation of

signal transduction

response to steroid

$10 \mathrm{E}-7 \quad 10 \mathrm{E}-4 \quad 10 \mathrm{E}-2$

Factor Cobound with CHD4

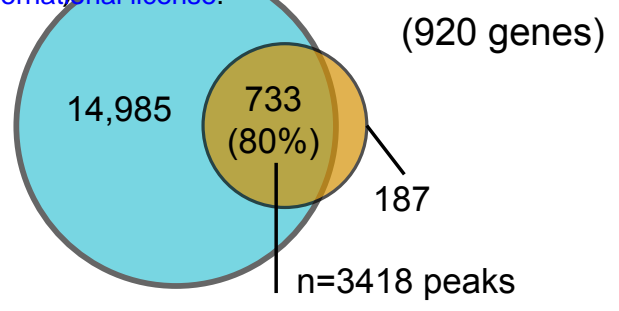

D

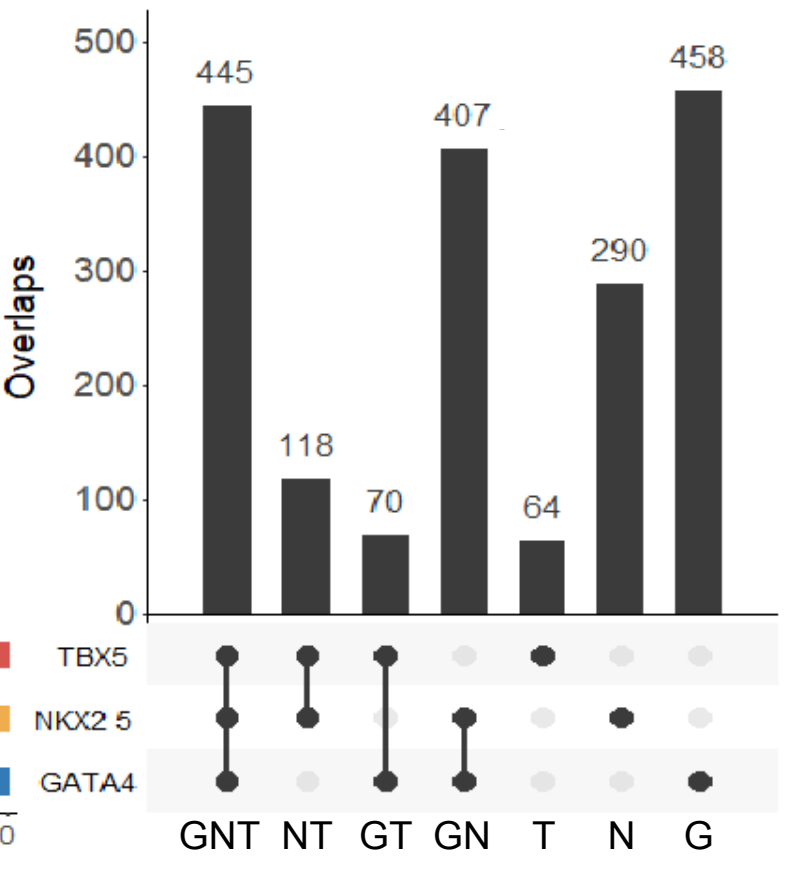

Overlap with CHD4 enomic Localization

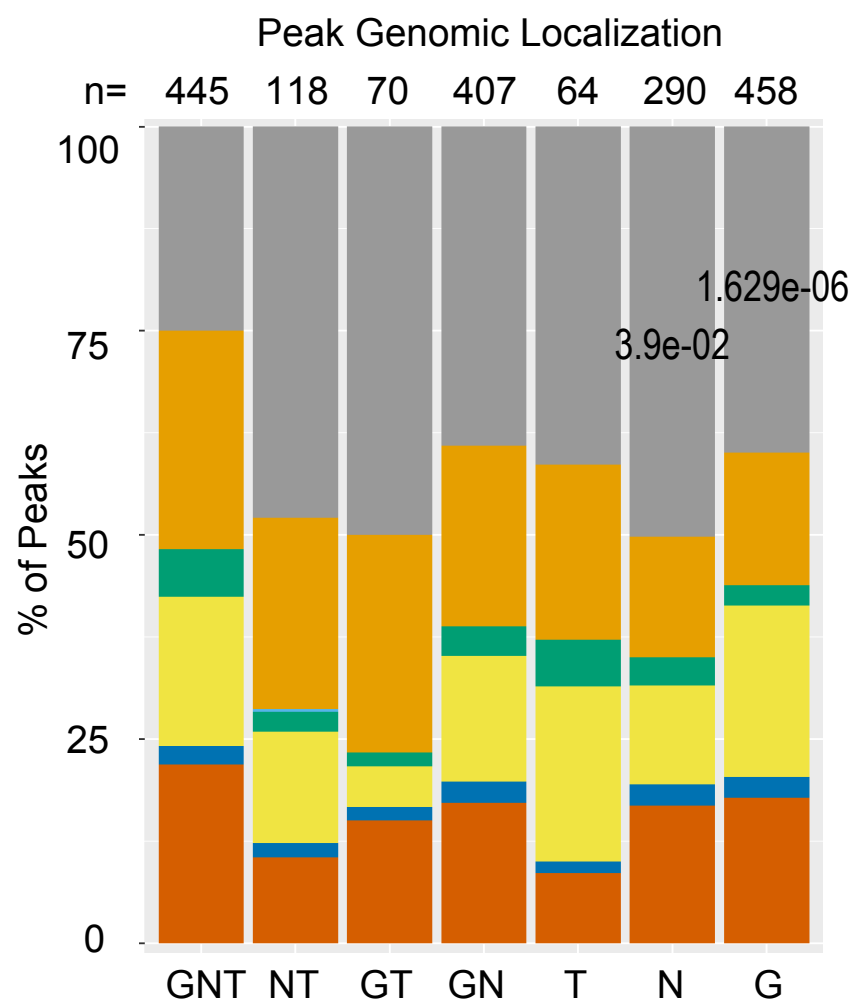

E

TSS $(<1 \mathrm{~kb})$

Promoter (1-10kb)

Exon
Intron

3' UTR

Intergenic 

available under aCC-BY-NC-ND 4.0 International license.

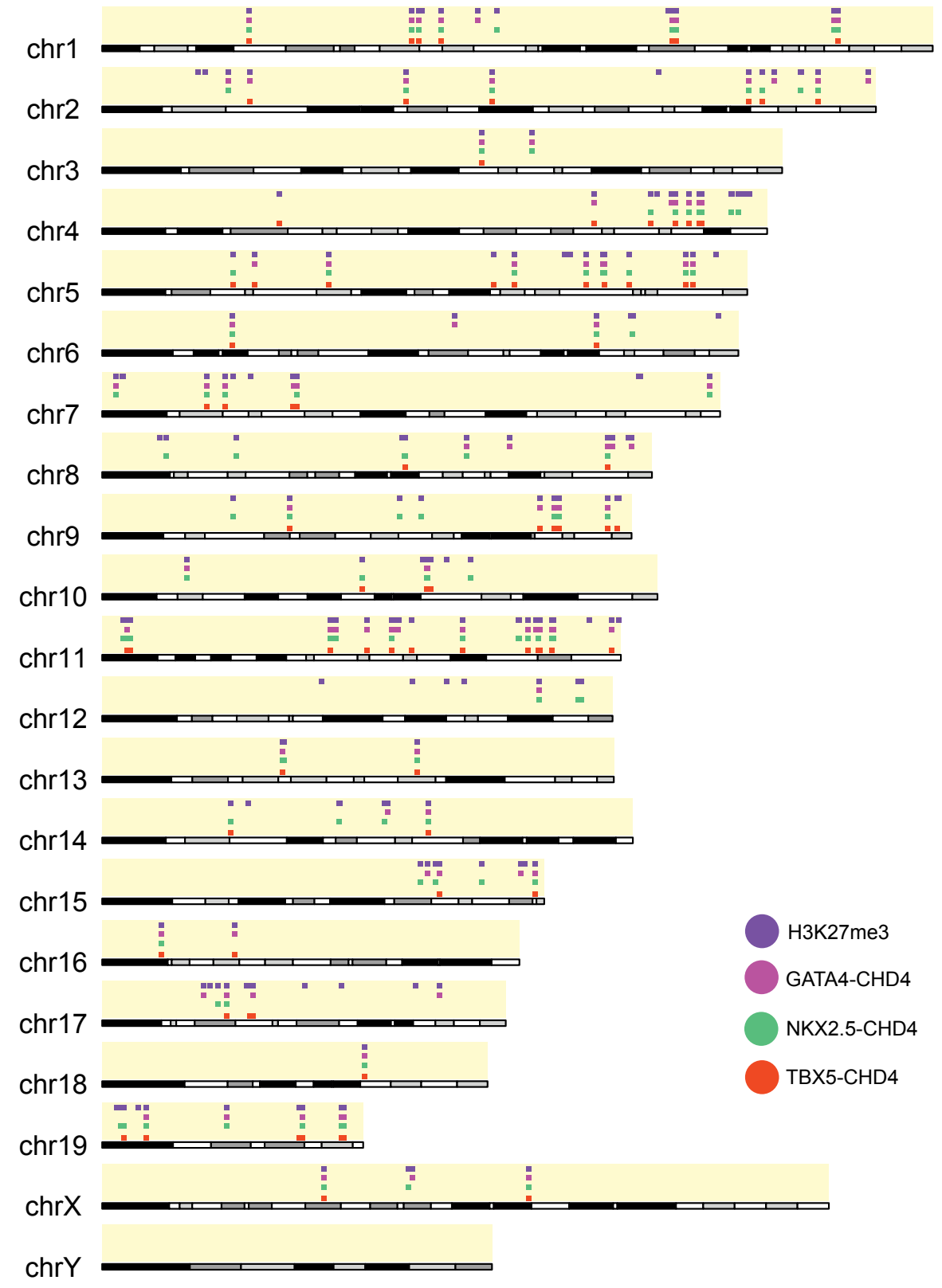




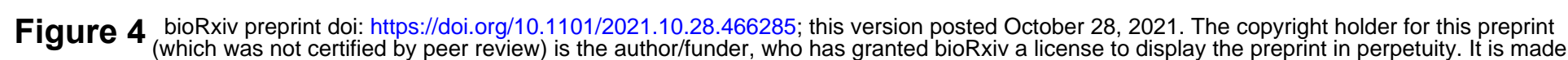

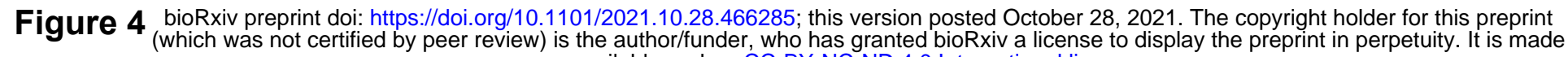
available under aCC-BY-NC-ND 4.0 International license.

A

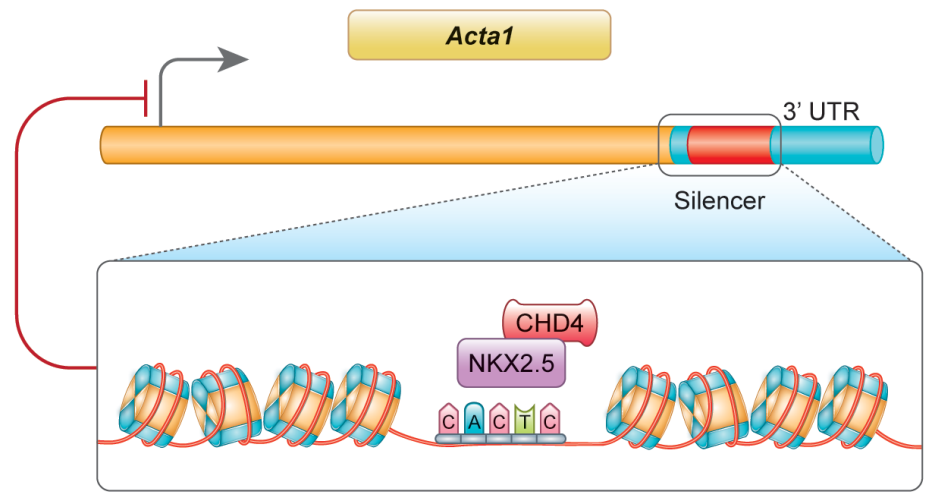

$\mathrm{B}$

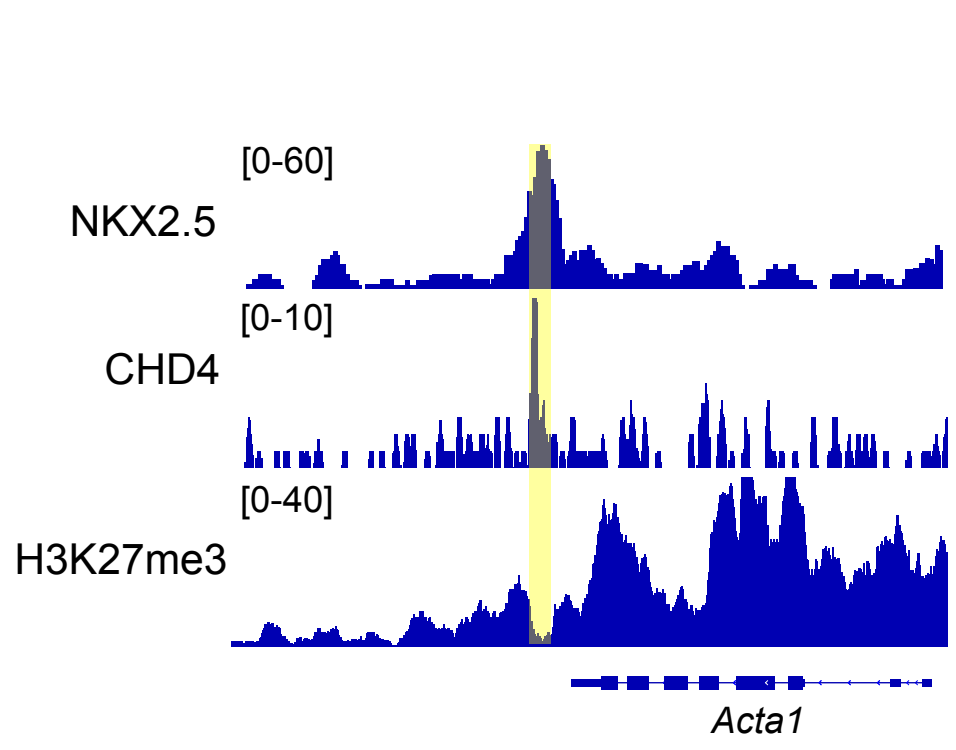

C

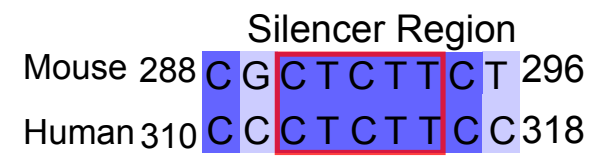

D

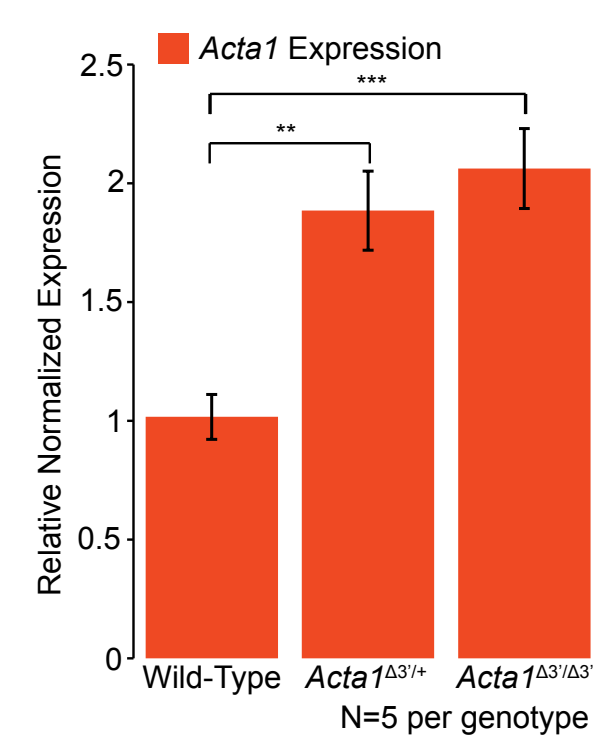


Figure 5 bioRxiv preprint doi: https://doi.org/10.1101/2021.10.28.466285; this version posted October 28, 2021. The copyright holder for this preprint (which was not certified by peer review) is the author/funder, who has granted bioRxiv a license to display the preprint in perpetuity. It is made available under aCC-BY-NC-ND 4.0 International license.

A

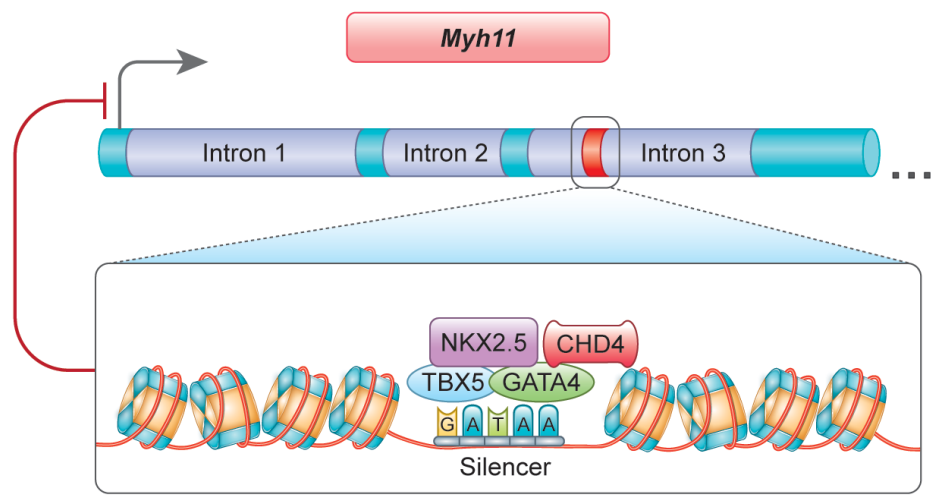

B
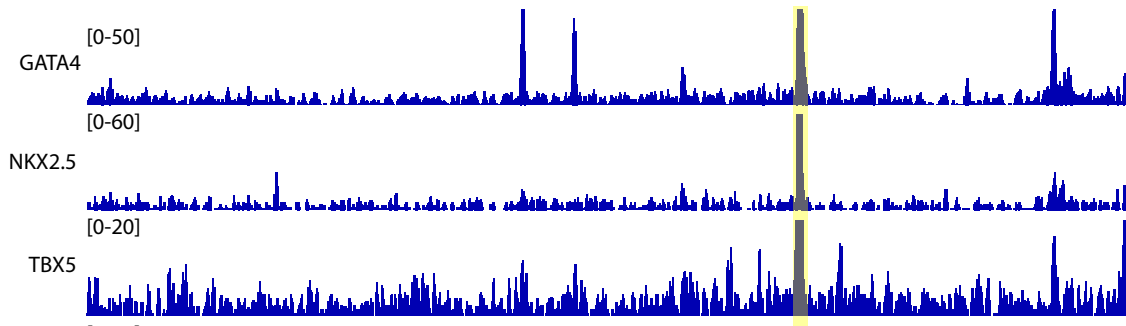
[0-10]

CHD4

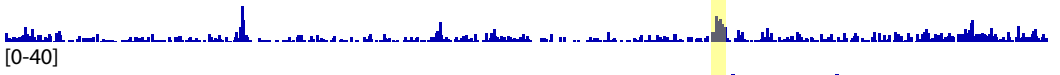
H3K27me3

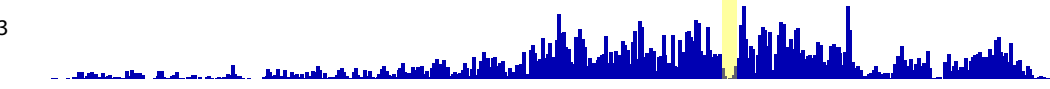

C

\section{Silencer Region \\ Mouse 23 - - -AATCTTATCTG C C 35 \\ Human 14TGGAAT CTTATCTGC- 29}

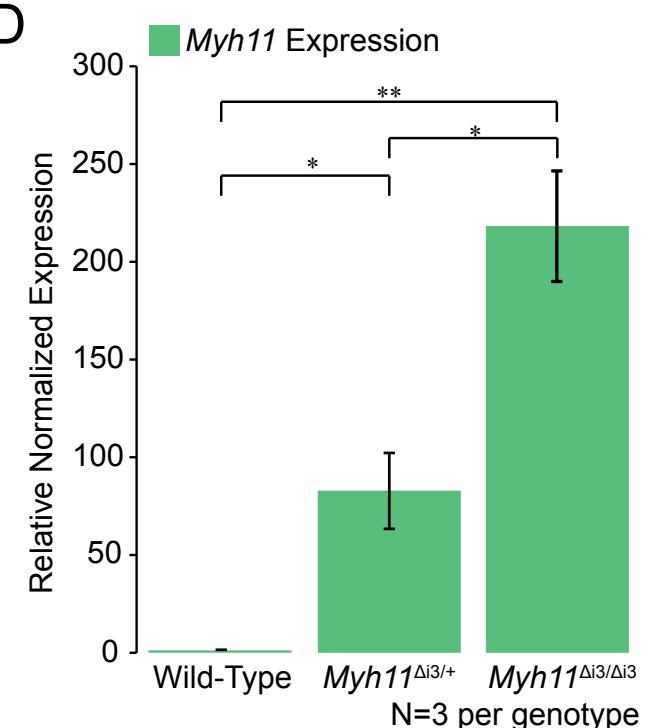




\section{Figure S2}

bioRxiv preprint doi: https://doi.org/10.1101/2021.10.28.46628反ihthis version posted October 28, 2021. The copyright holder for this preprint (which was not certified by peer review) is the author/funder, who has granted bioRxiv a license to display the preprint in perpetuity. It is made availabie under aCC-BY-NC-ND 4.0 International license.

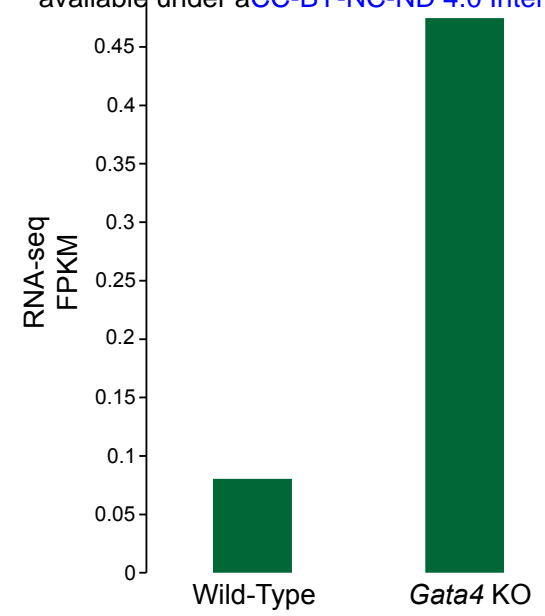

